\title{
THE NUCLEAR ARMS RACE: AN EVOLUTIONARY PERSPECTIVE*
}

\author{
Arthur A. Joyce \\ Department of Anthropology \\ Rutgers University \\ New Brunswick, New Jersey 08903
}

\begin{abstract}
This paper uses a Darwinian perspective to examine the nuclear arms race in the context of "arms races" in evolution and throughout human history. The rise of human "arms races," or escalatory intergroup competition, is traced to a variety of environmental triggers initiated during the Terminal Pleistocene/Early Holocene. These triggers removed extraspecific environmental constraints to escalatory intergroup competition in some areas of the world, making it reproductively advantageous for individuals to live in increasingly larger and more competitive groups. This process is linked to the development of social complexity and the intensification of intergroup competition, warfare, and arms production, culminating in the nuclear arms race. Historically, escalatory intergroup competition has been reproductively advantageous to elites because it enables them to acquire a disproportionately large share of resources. It is argued that the continuation of the nuclear arms race past a level of mutual assured destruction results from the benefits it provides to elites as well as a variety of evolved behavioral mechanisms that encourage in-group affiliations, out-group hostilities, and obedience to authority.
\end{abstract}

"Editor's Note: This article was selected for the Best Graduate Student Paper Award in 1987 by the Association for Politics and the Life Sciences in an international competition.
The nuclear arms race is the most significant threat to survival yet faced by the human species. A nuclear confrontation between the superpowers would end life as we know it on earth. While the initial destruction resulting from nuclear war would be severe, the probable long-term climatic effects of a nuclear war would result in extensive and permanent disruptions of the biosphere (Ehrlich et al., 1983; Peterson and Hinrichsen, 1982; Turco et al., 1983). Even relatively small nuclear exchanges have the potential to affect the climate and ecology of the earth severely (Turco et al., 1983). These factors make the nuclear arms race the paramount problem confronting humanity.

The study of the causes and effects of arms races has had a prominent place in political research since the pioneering work of Richardson (1935; 1960a, b). Likewise, the study of human warfare has a long tradition within the social sciences (Bloch, 1899; von Clausewitz, 1968; Davie, 1929; Fried, et al., 1968; Malinowski, 1941; Vayda, 1961; Fuller, 1945, 1961; Singer, 1979; Sorokin, 1937; Q. Wright, 1942). The advent of the nuclear arms race forty years ago intensified concern among social scientists about the problem of arms races and warfare. ${ }^{2}$ In response to the nuclear threat, a tremendous effort has been expended by diplomats, scientists, politicians, humanists, and other concerned individuals in an 
attempt to offer solutions to the problem of the arms race. The majority of these studies has focused on the political, psychological, economic, and military causes of the nuclear arms race (e.g., D. Adams, 1987; Bialer, 1985; Cusack and Ward, 1981; Mack, 1985, 1986; Nincic, 1982, 1983; Schell, 1982; Sheehan, 1983). These studies focus, however, on the proximate causes of the nuclear arms race while neglecting the evolutionary significance of arms race behavior and its ultimate causation. The application of Darwinian principles to social behavior during the last twenty years (see Hamilton, 1964; Trivers, 1971) has provided a rigorous paradigm for examining the ultimate causes of the behavior of humans as well as other organisms (see Alexander and Tinkle, 1981; Chagnon and Irons, 1979; Daly and Wilson, 1983; Krebs and Davies, 1984; Wiegele, 1982; White and Losco, 1986).

This article will use a Darwinian perspective to examine the evolutionary and historical roots of the nuclear arms race. Arms races are relatively recent phenomena in human history involving a competitive acceleration in arms production between two or more nations (Richardson, 1960a:23; Wallace, 1979:242; Wright, 1942:690). I will argue that the origins of the nuclear arms race can be viewed along a continuum of arms races in history which are manifestations of the more general phenomenon of escalatory intergroup competition. The history of human intergroup competition will be addressed by examining the selective basis for hominid social group formation. The rise of escalatory intergroup competition will be traced to a variety of environmental triggers initiated during the Terminal Pleistocene/Early Holocene. These triggers removed extraspecific environmental constraints to escalatory intergroup competition in some areas of the world, making it reproductively advantageous for individuals to live in increasingly larger and more competitive groups. This process will be linked to the development of social complexity, and the intensification of intergroup competition, warfare, and arms production, culminating in the nuclear arms race.

Furthermore, I will argue that escalatory intergroup competition favors the reproductive interests of elites by enabling them to acquire a disproportionately large share of resources. These benefits have encouraged elites to promote the arms race to a point which far exceeds any realistic consideration of national security. The ease with which the arms race is stimulated is also linked to a variety of proximate mechanisms that compel people towards intergroup competition and submission to authority. By framing today's problems in an historical context, this approach will provide a more comprehensive understanding of the nuclear arms race and, it is hoped, a contribution to its solution.

A Darwinian perspective views the causes of human behavior as congruent with other forms of organismic behavior. Behaviors result from and are subject to the forces of natural selection. Human behavioral responses are evolved proximate mechanisms and should act to maximize the inclusive fitness of individuals, except under novel evolutionary environments (Alexander, 1979; Flinn and Alexander, 1982). In this sense, a Darwinian perspective addresses questions concerning the environmental pressures which have caused human behavioral patterns based on predictions from inclusive fitness maximization. Unfortunately, the relationship between specific behaviors of individuals and inclusive fitness maximization is often unclear. This is due to the complex way in which a single behavior relates to the reproductive success of an individual, as well as the lack of knowledge concerning human behavioral ontogeny. When addressing more general patterns of human behavior, however, much of the "noise" of individual behavioral vagaries is eliminated. Numerous studies have shown conformity between behavioral patterns and predictions from inclusive fitness maximization (Alexander, 1979; Alexander and Tinkle, 1981; Betzig, 1985; Betzig and Turke, 1986; Essock-Vitale and McGuire, 1980; Gaulin and Schlegel, 1980; Masters, 1987; Turke, 1984). Thus, a Darwinian approach attempts to explain, in terms of inclusive fitness, why individuals follow their economic interests, live in particular types of social groups, follow leaders, go to war, or make alliances.

This article differs from previous Darwinian analyses of the nuclear arms race (Alexander, 1987) in taking a diachronic approach to the study of arms race behavior. Alexander (1987) has examined the validity of the various positions in the current debate over disarmament given a Darwinian understanding of behavior. He has also developed a series of important ideas concerning human social evolution, most notably the balances of power hypothesis. Alexander $(1971,1974,1975,1979,1981,1985$, 1987; Alexander et al., 1979; Alexander and Tinkle, 1968) has, however, almost exclusively utilized general evolutionary theory and comparative data to develop and evaluate his ideas. This article differs from Alexander's work in that it uses the archaeological, paleoenvironmental, historical, and ethnographic record to trace the history of human responses to changing environments that eventually led to the nuclear arms race. Most importantly, I discuss the environmental triggers and response processes which set in motion the sequence of escalatory intergroup competition that has led directly to the nuclear arms race. 


\section{The Selective Basis of Hominid Social Groups: Origins of Human Arms Races}

While the nuclear arms race is only thirty years old, arms races and accompanying phenomena, such as resource competition and disarmament movements, can be traced back to the earliest historical records (Bigelow, 1969:62-63, 1975:243; Dupuy and Hammerman, 1973) and, from archaeological data, into prehistory (Carneiro, 1970a; Roper, 1975; Webster, 1976). Furthermore, arms races can be viewed as a specialized form of intergroup competition involving overt aggression and often violent conflict between social groups. While rare among non-human animals, this phenomenon is exhibited by other social species such as the spotted hyena (Crocuta crocuta; Kruuk, 1972), wolves (Canis lupus; Mech, 1970), rhesus macaques (Macaca mulatta; Givens, 1975), olive baboons (Papio anubus; Givens, 1975), and chimpanzees (Pan troglodytes; Goodall, 1979). Thus, the nuclear arms race can be viewed along a continuum of arms races in the human past and more generally as a form of intergroup competition in nature.

If the problem of arms races is to be addressed as a specific form of intergroup competition then it is necessary to consider the selective pressures responsible for the formation of competitive social groups. Living in social groups inevitably creates additional costs to individuals, such as increased competition for resources and increased likelihood of disease and parasite transmission (Alexander, 1979:59). These factors should select against sociality except under special circumstances. They must be overridden by the ability of individuals to defend themselves against predators, or more effectively to locate and exploit resources when in groups than individually. The nature and size of social groups in particular species should represent a compromise between these competing forces.

Archaeological and comparative data indicate that throughout most of hominid evolutionary history social groups consisted of relatively small extended family bands (Service, 1962). Selective pressures which have been suggested to explain the evolution of hominid social groups through the Pliocene and most of the Pleistocene include competition with carnivores (Potts, 1984; Walker, 1984) or cooperative hunting of large mammals (Campbell, 1979; K. Hill, 1982; Issac, 1978; Laughlin, 1968; Walker, 1984; Washburn and Lancaster, 1968). These factors are insufficient, however, to account for the size of social groups during recent millennia (Alexander, 1979:221). Thus, an evolutionary compromise at relatively small group size, such as that of extended family bands, would be predicted if these were the principal selective forces affecting hominid social groups. The historic and prehistoric record demon- strates that human groups have instead become increasingly larger and more competitive over the last 12,000 years, culminating in today's nuclear arms race. This suggests that some other force is selecting for increasingly larger and more competitive social groups.

Recently, Alexander (1971, 1974, 1979, 1987; Alexander et al., 1979; Alexander and Tinkle, 1968) has hypothesized that intergroup competition was a significant selective pressure favoring social group formation during much of hominid evolutionary history. Additionally, he has argued that intergroup competition is the principal environmental pressure responsible for the evolution of social groups larger than extended families. Alexander (1979) calls this the "Balances of Power Hypothesis." It suggests that at some time in the past, predation pressure from other human groups became the force selecting for increases in social group size and intragroup cooperation. This hypothesis is consistent with explanations proposed by many social scientists concerning the development of the nation-state (see Bean, 1973; Carneiro, 1961, 1970a; Claessen and Skalnik, 1978, 1981; Cohen and Service, 1978; Durham, 1976; Fried, 1961, 1967; Gilpin, 1981; C. Tilly, $1975 \mathrm{a}, 1985)$ as well as many of the unusual features of human sociality (see Bigelow, 1969, 1975; Keith, 1949; Lorenz, 1966; Wilson, 1973).

This type of intraspecific selection can result in the type of synergistic effects seen in the nuclear arms race today. If groups are forced to compete for resources actively, the most powerful group will outcompete opposing groups. Power has usually corresponded to group size, whether from sheer force of numbers or increased productive capacities, giving a selective advantage to individuals living in larger groups. Individuals in larger, more powerful groups will be able to outreproduce individuals of less powerful groups due to their preferential access to resources. This will encourage individuals in other groups to strive to increase group size and power to overcome their adversary's preferential position with respect to resources. Increasing group size is achieved by intensifying production so as to increase reproduction. This process should continue to escalate unless extraspecific selective forces intervene and make further increases in group size maladaptive to individuals.

Variables such as increases in group size above that of extended families, increased intergroup competition and intragroup cooperation, and the rise of social stratification are associated with the development of social complexity that has occurred in many areas during the last 12,000 years. Most scholars who have addressed the origins of social complexity note the correspondence in time of the earliest evidence for these trends, with the massive world- 
wide environmental disturbances associated with Terminal Pleistocene deglaciation. Early evidence for productive intensification, such as the origins of agriculture in the Near East, Central and South America, as well as the origins of sedentary villages in the Near East, are often linked directly or indirectly to these environmental effects (Binford, 1972; M. Cohen, 1977:143-144; Flannery, 1969, 1986; Hayden, 1981; Redman, 1978; H. Wright, 1977). I suggest that Terminal Pleistocene environmental change also provided the trigger initiating escalatory intergroup competition. These shifts were brought on by the extinction of large mammals and the subsequent expansion of many seasonally available lower trophic level plants and animals.

Archaeological data from the Late Pleistocene demonstrates that predation on medium-to-large sized mammals was an important component of the hominid resource base, especially relative to later periods (Butzer, 1977; Hayden, 1981; Klein, 1973, 1977, 1979). Most medium-to-large bodied mammals are K-selected species (Hayden, 1981; Pianka, 1970). K-selected species tend to be extremely vulnerable to overexploitation and require much longer periods to reestablish optimal population levels relative to other organisms. Their great size, however, makes them resources which are easy to locate and which provide concentrated caloric and nutrient packages. Thus, when available, these animals were highly valuable and cost-effective to harvest with the available technology.

Hominids were the dominant large-mammal predators by the Late Pleistocene and would have faced competition for these resources primarily from other groups of hominids. As a result of the instability of these resources, selection would have favored either avoidance of competing social groups or brief, possibly violent (see Roper, 1969), confrontations resulting in the expulsion of one group from a contested area. ${ }^{3}$ Otherwise, hominid social groups would have congregated around favorable resource patches leading to the rapid overexploitation of populations of large mammals. Ultimately, this would have led to resource scarcity and disaster for all individuals concerned. This does not mean that other resources were not available or utilized by human populations during the Late Pleistocene. Undoubtedly, small animals and plants as well as larger scavenged animals made up a significant portion of the hominid resource base. It suggests only that individuals in groups that dispersed to avoid overexploitation of medium-to-large bodied mammals would have had a selective advantage relative to individuals remaining in resource depleted areas. Thus, the susceptibility of K-selected mammalian populations acted as an extraspecific environmental constraint limiting human intergroup competition.
Large mammal extinctions at the end of the Pleistocene (Martin and Klein, 1984; Meltzer and Mead, 1983) eliminated this extraspecific constraint in many areas. This forced human populations to emphasize the exploitation of alternative food sources. Emerging postglacial environments were characterized by an increase in temperate and tropical forest habitats and animal populations such as anadromous fish, shellfish, and migratory waterfowl, as well as many edible plant species (Bryant and Holloway, 1985; Butzer, 1971:547-551; Flannery, 1986; Lamb, 1977; Redman, 1978; H. Wright, 1977). Human populations began to rely more extensively on r-selected resources such as plant foods, fish, and fowl (Binford, 1972; Butzer, 1977; Flannery, 1969; Hayden, 1981). Unlike large mammals, r-selected resources have rates of replacement and population densities which make them very difficult to overexploit. These resources also tend to have distributions which are clumped both spatially and temporally (Pianka, 1970). They can be extremely abundant, but their availability at particular locations is often unpredictable.

The abundance and distribution of r-selected resources brought groups together around productive resource patches. Active intergroup competition would have resulted. Furthermore, expansion of human populations into practically all remaining terrestrial habitats during the Late Pleistocene decreased the ability of groups to migrate into unoccupied areas to avoid competition (see M. Cohen, 1977). Individuals in larger groups which were able to exclude smaller groups from favorable resource patches would have had a selective advantage. This type of intergroup competition does not necessarily imply warfare, as social mechanisms for assessing the risk of conflict were undoubtedly developed (e.g., the pig festivals of New Guinea). This made possible the type of escalatory intergroup competition and increasing group size and social complexity seen throughout recent human history.

The unpredictability of these resources favored the development of social networks that communicate information about resource distributions. Individuals exploiting the most predictable resources such as anadromous fish and migratory waterfowl enjoyed especially effective harvests and would have had greater reproductive success. This was also true for individuals who were able to cultivate plant and animal species, making them more predictable and productive, and eventually resulting in domestication (see Flannery, 1986). These processes also favored the emergence of sedentary villages located preferentially in productive resource zones.

Social stratification and the rise of complex societies can be explained as direct results of continued 
escalatory intergroup competition (Masters, 1983, 1986; Willhoite, 1980, 1986). This resulted primarily from the diverging reproductive interests of individuals in increasingly larger groups. As social group size rose beyond that of extended families, individuals interacted increasingly with non-relatives. This caused the reproductive interests of individuals within groups to increasingly diverge (see Alexander, 1979, 1985; Betzig, 1982, 1985; Chagnon, 1979a, 1981). The redistribution and levelling of resources throughout a society was no longer reproductively advantageous due to kin selection, as it had been when social groups consisted primarily of close relatives. This made it increasingly advantageous for individuals to accrue disproportionate amounts of resources relative to other group members through manipulation and/or force.

Intragroup conflict and competition intensified, necessitating the development of social mechanisms to mediate conflict and promote reciprocal relationships. Individuals in roles involving conflict mediation had an advantage in social deception and exploitation because of the power conferred by their social position. These individuals were able to gain preferential access to resources, thereby increasing their power base and the degree of social stratification in general. Those in power were able increasingly to influence ideological, judicial, moral, and governmental systems to maintain and support their power base. Concomitantly, social institutions involved in conflict mediation became more complex as the elites who controlled these institutions gained power and influence. Relatively small-scale and powerless institutions such as clans and "big-men" evolved into "ranked" lineages with hereditary chiefs, and finally into the immensely powerful governments of today's nation-states (Flannery, 1972). While these processes would have placed an increasingly large proportion of society at a disadvantage with respect to resources, the alternatives of leaving their society or revolting against those in power usually involved considerably more risk. Coupled with these changes in the social environment, new and more efficient technologies were developed to gain a competitive edge over other groups by increasing productivity and military capabilities.

The past 12,000 years have been witness to the development of increasingly more complex societies often characterized as tribes, chiefdoms, and states. The archaeological and historical record of this period is consistent with these ideas concerning the rise of social complexity (Flannery, 1972; Fried, 1967; Price, 1984; Service, 1971, 1975; Q. Wright, 1986). The correspondence between increasing group size, social stratification, and productive intensification, the use of secular or religious institutions by elites to control the masses, and the relationship between intergroup competition and intragroup cooperation are all characteristic of this period. The wide literature on state formation is also consistent with this model. Factors recognized as important in the rise of states include environmental and social circumscription, population growth, warfare, productive intensification with surpluses being disproportionately transferred to elites, and the ideological justification of power differentials usually through state religions (Carneiro, 1970a; Claessen and Skalnik, 1978, 1981; R. Cohen, 1984; Cohen and Service, 1978; Patterson and Gailey, 1987; C. Tilly, 1985).

Cross-cultural comparative data are consistent with this model of the development of social complexity (Betzig, 1982, 1985; Strate, 1982). Betzig (1982) collected data from twenty-four well-known societies with social organizations ranging from the simplest egalitarian societies such as the !Kung and the Andaman Islanders through "early state" societies such as the Zulu and Tonga. High correlations were found among the following variables: (1) group size; (2) hierarchical complexity; (3) asymmetry in the resolution of individual conflicts with higher status individuals having an advantage; (4) perquisites taken by third parties mediating conflicts (the third parties were usually high-status individuals or institutions controlled by these individuals); and (5) degree of polygyny attained by individuals at the top of the social hierarchy. These data are consistent with the prediction that "to the extent that conflicts of interest among individuals in a society are not overridden by common interest, individuals should exploit hierarchical positions of strength to maximize inclusive fitness at the expense of others in the group" (Betzig, 1982). Thus, as group size rose due to intergroup competition, inequalities in social and reproductive success increased because the social environment made it advantageous for those in power to exploit the less powerful.

\section{The Balances of Power Hypothesis and Holocene Sociocultural Diversification}

In the preceeding discussion the balances of power hypothesis was evaluated with archaeological, paleoenvironmental, ethnological, and historical data. A correspondence was shown between the removal of various extraspecific environmental constraints on escalatory intergroup competition during the Terminal Pleistocene/Early Holocene with the rise of social complexity. Contemporary societies, however, vary greatly in regard to measures of social complexity, including population size, productive capacity, technological complexity, and social stratification (see Murdock, 1949). This indicates that escalatory intergroup competition may have only occurred under special ecological conditions. This variability must be explained to understand why 
complex societies and, eventually, nuclear powers arose.

The diversity of human societies can be explained by the variable effects of extraspecific environmental constraints differentially compromising escalatory intergroup competition (fig. 1). In areas where populations of large mammals persisted as an important food source, and/or where r-selected resources did not significantly expand, escalatory intergroup competition remained disadvantageous. In these habitats, small-scale societies persisted unless influenced by more complex societies. Examples include Eskimo and Algonkian populations of northern North America (Service, 1962), the precontact bisonhunters of the western Great Plains (Gunnerson, 1972; Wedel, 1978), and African Savanna populations such as the !Kung (Lee 1968, 1969) and the Hadza (Woodburn, 1968).

In regions where ecological conditions limited productive intensification, an evolutionary compromise was created at some level of social complexity above that of extended family bands. For example, recent archaeological data suggest that human populations in the New Guinea Highlands were practicing horticulture as early as 9000 B.P. Despite this early evidence of productive intensification, ecological factors, notably the restriction of arable land to small intermontane valleys and the nature of available domesticates, limited agricultural productivity (Golson, 1977). Indigenous populations reached a "tribal" level of cultural complexity (Service, 1962) characterized by intense intergroup competition expressed most dramatically by frequent episodes of "ritualized" warfare (see Meggitt, 1977; Morren, 1984; Rappaport, 1968; Vayda, 1976).

In other regions resources remained sufficiently dispersed and unpredictable to have suppressed escalatory intergroup competition relative to areas where complex states first arose (Carneiro, 1970a). These areas included much of North America and Europe, where trends towards social complexity have been observed in the archaeological record, but where states did not develop indigenously before disruption by more complex societies (Braun and Plog, 1982; Dennell, 1983; Renfrew, 1978; Renfrew and Sheenan, 1982; Trigger, 1981).

Complex stratified states arose in regions with the lowest intensity of extraspecific checks to escalatory intergroup competition. Archaeological data has shown that the sequence of development of the state in Mesoamerica involved productive intensification, intergroup conflict, and increases in social and technological complexity as well as social group size. This sequence began with a shift from an emphasis on hunting large mammals in the Terminal Pleistocene/Early Holocene to a focus on aquatic and floral resources concentrated in coastal and riverine environments during the Middle Holocene. Finally, increasingly intensive forms of agriculture were developed, accompanied by increasing social stratification culminating in the rise of the state (Flannery, 1965, 1972; Flannery and Coe, 1968; Webster, 1976; Willey, 1966; Q. Wright, 1986). Mesoamerican state societies were eventually decimated by the most potent selective force affecting recent human populations, contact with a more powerful group resulting in exploitation and the introduction of deadly pathogens.

However, many societies during the Holocene did not necessarily proceed inexorably in the direction of social complexity. Numerous archaeological examples, such as the Classic Maya collapse and the decline of Fremont society in the southwestern United States, demonstrate that the trend towards increasing social complexity is often reversed. Changes in social and biophysical environments that caused extraspecific constraints on intergroup competition to be exceeded made further escalations counteradaptive. This threshold was usually first reached and exceeded by less powerful segments of societies. This resulted in intense intrasocietal conflict as those with power resisted change, eventually leading to societal collapse. Furthermore, while the preceding examples illustrate the general processes leading to sociocultural diversification in the Holocene, it should be emphasized that particular developmental sequences were unique and extremely complex, involving numerous social, cultural, and ecological factors which are beyond the scope of this article.

This model of Holocene sociocultural diversification is supported by historical and ethnographic data. If social complexity is a product of the effects of a history of escalatory intergroup competition, then measures of the intensity and efficiency of conflict between populations should correlate with social complexity. Historical data clearly demonstrate that as social complexity increased, intergroup competition rose in the form of more destructive military technologies and warfare (Andreski, 1968; Dupuy, 1984; Fuller, 1945, 1961; Otterbein, 1970:44-48; Q. Wright, 1942). This hypothesis has also been confirmed by a variety of comparative studies of conflict and violence among contemporary societies (Andreski, 1968; Broch and Galtung, 1966; Haas, 1965; Otterbein, 1970; Ross, 1985, 1986).

In small-scale societies, community size and the degree of intercommunity cross-cutting ties are related to the scale at which intergroup competition is most intense (see Chagnon, 1968, 1981; Ross, 1985, 1986). Social group size and cohesion are greater with increased intercommunity conflict (Chagnon, 
$1968,1979 b, 1981)$, while communities that share an identical enemy are more likely to have cross-cutting ties promoting alliance formation (Divale, 1974; Ember, 1974; Ember and Ember, 1971; Ross, 1985, 1986).

A recent cross-cultural study of ninety preindustrial societies by Ross $(1981,1985,1986)$ provides more detailed information on the relationship between social structure and conflict. Ross (1986:454) found a positive association between socioeconomic complexity and both conflict within a society and external warfare. This is consistent with the hypothesis that increasing social complexity should be accompanied by both increasing intergroup and intragroup competition. However, Ross (1985:558) notes that more complex socioeconomic populations tend to have either high internal or high external conflict. A major determining factor between these two conditions seems to be the degree of political centralization, which inhibits internal conflict (Ross, 1986:451). These data are consistent with a Darwinian view of social evolution. Increasing internal conflict is predicted with rising population size and social stratification, while greater political centralization would enhance the degree of political coordination and control that elites can exert to suppress internal dissension.

Despite these correlations, even societies with similar degrees of complexity vary greatly in their expression of violence, aggression, and warfare (Otterbein, 1970; Ross, 1986). Among small-scale, politically uncentralized societies the expression of violence and warfare relates to factors including intercommunity cross-cutting ties, the presence of fraternal interest groups, and the degree of polygyny (Otterbein, 1968, 1970; Ross, 1985, 1986). The frequency of contact with other societies increases the level of external conflict and warfare (Chagnon, 1968:114; Ross, 1985:568). Ecological factors also affect the nature of intergroup competition and warfare in small-scale societies (Chagnon, 1968; Ferguson, 1984; Meggitt, 1977; Rappaport, 1968; Vayda, 1961, 1976). Psychocultural factors play an important role in the expression of violence (Ross, 1985, 1986; Volkan, 1985). The continued study of these relationships should provide useful hypotheses concerning intergroup competition and the rise of social complexity.

\section{The Balances of Power Hypothesis and the Rise of Militarism}

In the preceding section it was argued that the expression and rate of escalatory intergroup competition differed in various regions worldwide due to varying ecological conditions. This resulted in a diversity of human societies in relation to variables constituting social complexity. In regions where escalatory intergroup competition continued unimpeded by extraspecific constraints, complex states arose characterized by the presence of powerful elites. In the following discussion I will argue that success in intergroup competition and the maintenance of external threats has disproportionately favored elite interests in nation-states. This has resulted in an intensification of intergroup competition, arms production, and warfare, leading eventually to the nuclear arms race.

As complex societies arose, elites in these societies would have benefited from success in intergroup competition because economic and political systems provided them with a disproportionate amount of resources gained in victory. However, elites also benefit in that the maintenance of a threat, whether real or illusory, enhances group cohesion, thereby reducing internal dissension (Alexander, 1979:238). The maintenance of order and group cohesion in the face of competing groups is advantageous to nearly everyone because it increases the ability of the group to provide an aggressive defense. As external threats decrease in intensity, however, the relative advantage of group unity to individuals with relatively restricted access to resources (i.e., the lower classes) is outweighed by these unequal relationships of power within the society. Thus, internal dissension among the lower classes may increase because upper class exploitation becomes more significant than any external threat. In extreme cases this relationship may shift sufficiently to make a socialist revolution viable for a large proportion of the lower classes as well as other parties interested in the overthrow of the state. In this case there is an effective shift in the group defined as the principal external threat, from other nations to the upper classes.

Historical evidence demonstrates that elites gained from intergroup competition and warfare during the development of the nation-state in Europe (Lane, 1966; McNeil, 1982; Rasler and Thompson, 1985a, 1987; C. Tilly, 1975a, 1981, 1985). The historical process of European state formation can be simplified to a consideration of four interacting processes: war making, state making, protection, and extraction (Tilly, 1985; Rasler and Thompson, 1987). Ruling elites made war with other ruling elites to eliminate their competitors and gain additional power. To develop the means for successfully waging war, elites extracted resources from the people including taxes, food, and conscripts. The act of extraction also involved the elimination of internal competitors of ruling elites through violence, coercion, or cooptation. Extraction was achieved by offering the people protection from either external or internal threats. Warfare, extraction, and protection served to eliminate internal rivals of ruling elites, 
further consolidating their power and building the state.

Since warfare was the rationale for protection and extraction, ruling elites gained from promoting intergroup competition, if not warfare. These factors have led C. Tilly (1985; see also Rasler and Thompson, 1987) to characterize war making and state making as an organized crime perpetuated by the ruling elite on the citizenry. Tilly (1985:171) states:

\begin{abstract}
To the extent that the threats against which a given government protects its citizens are imaginary or are consequences of its own activities, the government has organized a protection racket. Since governments themselves commonly simulate, stimulate, or even fabricate threats of external war and since the repressive and extractive activities of governments often constitute the largest current threats to the livelihoods of their own citizens, many governments operate in essentially the same ways as racketeers.
\end{abstract}

Intergroup competition and warfare favored elite interests due to territorial expansion, eliminating external and internal rivals, increasing intragroup cohesion, and extracting greater amounts of resources from the masses to support the state and especially its ability to make war (Bean, 1973; Braun, 1975; Howard, 1984; Rasler and Thompson, 1985a, 1987; C. Tilly, 1975a, 1985). These factors encouraged elites to stimulate and escalate intergroup competition and warfare in Europe leading to the formation of increasingly more powerful and competitive states. That the most powerful states have been the most warlike (Bremer, 1980; Q. Wright, 1964:168) suggests that elites in these nations were more likely to engage in war because of the greater probability of victory. Maoz (1983) has shown that states initiating disputes during the nineteenth and twentieth centuries were disproportionately likely to be victorious. These data suggest that elites more often initiated disputes when the balance of power was in their favor.

The effects of warfare stimulated by self-interested elites in the transition from feudal kingdoms to modern nation-states in Europe has received considerable attention from political scientists (e.g., Bean, 1973; Rasler and Thompson, 1983, 1985a, 1985b, 1987; Tilly, 1975a, 1981, 1985; Winter, 1975). The period from the tenth century onward saw a diminution in the number of ruling elites as the victors consolidated power (Bean, 1973; Finer, 1975; Tilly, 1975b). Early in this period ruling elites acted to monopolize the use of force and to legitimize this monopoly to neutralize internal rivals (Finer, 1975; Tilly, 1985). As power consolidation continued, the scale of intergroup competition and warfare escalated, leading to frequent and increasingly bloody wars. Elites began to remove themselves from ac- tual combat and, from the fourteenth and fifteenth centuries onward, relied on professional armies to do their fighting (Duby, 1974; Hale, 1979; McNeil, 1982:63-73). More resources were provided to the military to increase its size, technological sophistication, and destructive capability, making warfare increasingly hazardous to the actual participants (Keegan, 1976).

Escalating intergroup competition and warfare required the extraction of greater amounts of resources from the masses (see Bean, 1973; McNeil, 1982; Rasler and Thompson, 1983, 1985a, 1985b, 1987; C. Tilly, 1975a, 1981, 1985; Tilly and Tilly, 1981; Winter, 1975). Exploited materials included both natural and human resources, especially involving conscription and taxation. Intensified extraction was also manifest in the competition between European nations for the exploration, exploitation, and colonization of new lands such as the Americas, sub-Saharan Africa, India, and China beginning in the fifteenth and sixteenth centuries. The large entrepreneurial and colonial empires of the Dutch, Portuguese, Spanish, French, and especially the English opened up vast areas for the exploitation of critical resources with which to gain a competitive edge in the balance of power in Europe.

As exploitation by elites intensified, the relative risk of revolution decreased for the lower classes. This led to the tax, conscription, and food rebellions beginning in the thirteenth century (Kuhnle, 1981; C. Tilly, 1975b, 1975c; Tilly and Tilly, 1981) and to the great revolutionary movements of the last two centuries (Postgate, 1969; C. Tilly, 1975d). Ruling elites responded to this internal pressure by building up police forces and the judicial system to suppress rebellion (Bayley, 1975). Patriotic and ethnocentric ideologies began to be used to promote affiliation with the state.

Ruling elites began to form coalitions with social classes that could aid them in extraction and suppression of internal rebellions (C. Tilly, 1975a, 1985; Rasler and Thompson, 1985). These classes consisted primarily of wealthy landowners, bankers, and merchants who could promote the transfer of capital and agricultural resources to the state. In return for their assistance, these privileged classes were given preferential treatment with regard to extraction costs and protection from both internal and external rivals. This increased the interest of these economic elites in the state and military expansionism.

Coalitions between economic and ruling elites increased the linkage between market economies and the military, and allowed a greater proportion of resources to be transferred into arms production. A result of this linkage has been the appearance and 
increasing intensity of arms races during the last 600 years (McNeil, 1982). McNeil (1982:69-70) states:

\begin{abstract}
Commercialization of organized violence came vigorously to the fore in the fourteenth century when mercenary armies became standard in Italy. Thereafter, market forces and attitudes began to affect military action as seldom before. The art of war began to evolve among Europeans with a rapidity that soon raised it to unexampled heights. The history of the globe between 1500 and 1900 testified to Europe's uniqueness in these matters military that European states and private entrepreneurs inaugurated during the fourteenth century.
\end{abstract}

Early examples of classic military arms races include the escalatory production and development of artillery between France and Burgundy from 1465 to 1477 , and the various naval arms races between France and England throughout the seventeenth and eighteenth centuries.

The effects of state building processes led to increasingly more stratified, specialized, and complex forms of social organization, resulting in the rise of nation-states in the sixteenth and seventeenth centuries (C. Tilly, 1975a). Military expansionism created vast military bureaucracies led by powerful elites (Finer, 1975). Administering taxation, conscription, and policing activities gave rise to immense civilian bureaucracies with a stake in the maintenance of the state (Ardant, 1975; Fischer and Lundgreen, 1975; C. Tilly, 1981). The symbiotic relationship between economic and ruling elites allowed economic elites to accumulate tremendous amounts of capital, eventually rivaling and surpassing the capital resources of ruling elites (C. Tilly, 1985). The increasing burden of extraction on the least powerful segments of society resulted in both protest and emigration. Ruling elites in at least some nations responded with social welfare programs and labor reforms which also gave rise to large bureaucratic institutions (Katznelson, 1985; Kuhnle, 1981; Fischer and Lundgreen, 1975). Democratization and expanding enfranchisement of the middle and lower classes also gave increasing numbers of people input into policy (Kuhnle, 1981).

Intrasocietal diversification significantly complicated the relationship between elites and intergroup competition. Political, economic, ideological, and military control in early states was almost exclusively in the hands of a small aristocracy usually consisting of several kinship groups (Skalnik, 1978:609-610). Modern nation-states consist of a variety of coalitions with varying degrees of interest in state expansionism through intergroup competition. However, the interests of the most powerful ruling, economic, and military elites continues to coalesce around intergroup competition and state building (Fitch, 1985; Rosen, 1973).
The industrial revolution dramatically increased the ability of ruling elites to wage war on one another (Finer, 1975; Fuller, 1961, 1969). ${ }^{4}$ Industrialization allowed a tremendous expansion in arms production and development, as well as profits for military industrialists. The relationship between military and economic expansionism seems to have stimulated industrialization in general ( $P$. Deane, 1975 ) and given rise to a new and extremely powerful elite coalition known as the military-industrial complex (Koistinen, 1967; Rosen, 1973). The intensification of intergroup competition, especially as manifest by arms races and warfare, has resulted in the development of increasingly complex and destructive technologies of warfare (Dupuy, 1984; Fuller, 1945; Headrick, 1981; McNeil, 1982; Winter, 1975; Q. Wright, 1964:51-63). This trend has culminated in the mass slaughter of the two World Wars and the precarious balance of nuclear terror that currently threatens human survival.

\section{The Balances of Power Hypothesis and the Nuclear Arms Race}

The nuclear arms race is the present-day manifestation of escalatory intergroup competition. The development of nuclear weapons, and the nuclear arms race, can be linked directly to the intensification of intergroup competition, arms production, and warfare seen during recent centuries. In this section the history of the nuclear arms race will be discussed in terms of escalatory intergroup competition. It will be argued that the attainment of mutual assured destruction (MAD) should have shifted intergroup competition to other realms. Its continued intensification is stimulated by the actions of elites who, despite the inherent hazards, continue to benefit relative to other individuals.

The first two decades of the nuclear arms race can be seen as a classic example of escalatory intergroup competition. Prior to the 1960s, the United States had followed a defense policy aimed at massive retaliation in response to any Soviet aggression, nuclear or otherwise (Fallows, 1981; Nincic, 1982; D. Rosenberg, 1983; Sheehan, 1983). This was a logical short-term strategy for U.S. policy makers in that the balance of power favored the United States because of their dominant nuclear arsenal. War was to be avoided and security maintained because deterrence could be insured by threatening a retaliation that was disproportionately greater than the provocation.

As would be expected, the Soviets sought to alter the balance of power and by the late 1950s they had achieved a nuclear arsenal that was competitive with that of the United States (Nincic, 1982:88-89; Wohlstetter, 1957). This led to a change in American nuclear strategy to one of deterrence by mutual 
assured destruction (Powers, 1982). This policy asserts that deterrence is mutual and based on the expectation that nuclear retaliation would follow a nuclear attack and this would prevent the occurrence of either. Conventional attacks would be met with conventional responses as long as possible. The major prerequisite of MAD was that both sides maintained a second strike "countervalue" capacity. This implies the possession of a nuclear arsenal sufficiently capable of weathering an initial full-scale assault to respond with a sufficient level of damage on the aggressor. The knowledge that intolerable devastation could not be avoided would prevent a first strike from ever occurring. The Soviets also chose to follow a strategy of mutual assured destruction (Garthoff, 1978; Jones, 1978), and by the early 1970s it was estimated that both the United States and the Soviet Union had achieved a countervalue capacity (Nincic, 1982:92-93).

The achievement of MAD should have led to a relaxation in the nuclear arms race. Once each side was assured of its ability to destroy the other in a nuclear confrontation, intergroup competition should have shifted to other areas such as non-military industrial and technological development. Nonetheless, the nuclear arms race and military spending has increased dramatically throughout the 1970s and 80 s and it shows no signs of abating (Blechman and Utgoff, 1986-87; Nincic, 1982; Powers, 1982).

Potentially many factors could account for the continued intensification of the nuclear arms race beyond MAD (Allison and Szanton, 1976; Halperin, 1974; Nincic, 1982). Distrust between the leaders of the U.S. and the U.S.S.R. could be inhibiting attempts to stabilize nuclear proliferation. However, the efficiency of surveillance devices, especially spy satellites, substantially negates the possibility of effective deception by one government. Furthermore, recent attempts at limiting nuclear arms have instead become rationale for producing new weapons systems as "bargaining chips." Technological inertia caused by the complexity of these weapons systems may also impede efforts to curb the nuclear arms race. Similarly, the bureaucratic inertia of both superpowers tends to inhibit drastic policy shifts which might curb the arms race. The continuation and intensification of the nuclear arms race also favors elite interests in the same way that intergroup competition has done since the rise of complex societies.

The continuation of the nuclear arms race provides an external threat of grand proportions to promote group cohesion and channel resources directly and indirectly to many military, ruling, and economic elites (Lifton and Falk, 1982; Nincic, 1982, 1985). Nincic (1982) has concluded that the intensification of U.S. nuclear arms capabilities has been primarily a result of endogenous factors, including economic benefits to industrial and ruling elites and the influence of powerful military and industrial interest groups on politicians. Furthermore, in the United States, the decision-making process involved with military appropriations, coupled with technological and bureaucratic inertia, favor military-industrial interests (Brown, 1982, 1987; Holland, 1987; Holland and Hoover, 1985; Kurth, 1971). The structure of decision making is such that early phases are carried out by elites whose interests coincide with military expansionism (e.g., the military, industrialists and technocrats in industries with large Department of Defense contracts). Outside interests tend to become more influential during later stages, but by this time technological and bureaucratic inertia often make it difficult significantly to counteract decisions made early in the process.

Elites who benefit from the arms race should be least in favor of arms control and nuclear weapons stabilization. They should encourage the arms race as long as the risk of nuclear annihilation is not too great. Since the elite have greater control over information and policy than other classes, they can both direct policy to stimulate rather than inhibit the arms race, and present the arms race to the public as necessary or inevitable. Thus, the relationship between external threats, group cohesion, and the maintenance of social stratification appears to favor the continuation of the nuclear arms race despite the attainment and possible realization of mutual assured destruction.

The nuclear arms race clearly favors military elites by providing them with an incredible array of resources to command as well as influence in regard to military contracts and political policy. The Pentagon's policy of continually demanding and rationalizing the intensification of arms production supports this assertion (see Proxmire, 1970). Strategic doctrines of both superpowers are largely designed publicly to justify new weapons systems, although their relationship to national security has been rather tenuous (Nincic, 1982:107).

The arms race is advantageous to ruling elites in that security from foreign threats is a highly emotional issue, well-suited to political rhetoric and debate (see Cannon, 1975; Mack, 1985; Nincic, 1982, 1985; Lifton and Falk, 1982; Stein, 1985). Defense against external threats may appeal to evolved behavioral mechanisms involving xenophobia, especially if intergroup competition has been an important factor in hominid evolution (Freedman, 1984; Johnson, 1986; Reynolds et al., 1987; van den Berghe, 1981; Volkan, 1985; Willhoite, 1977). Nincic (1985) has argued that ruling elites promote external rivalries to divert attention from internal problems. The social cohesive affects of this type of political 
rhetoric may be more important in relatively closed societies such as the Soviet Union, where it can act to diffuse or suppress dissension. Recent political history in the United States suggests that being viewed as soft on "defense" is potentially more damaging than being viewed as "hawkish." However, given its great destructiveness, actual warfare during recent history has often proven detrimental to ruling elites (Cotton, 1986; Stoll, 1984), even promoting conditions favorable to revolution (Laqueur, 1968; Tilly, 1975b:74). Thus, ruling elites today benefit more from promoting intergroup conflict and competition, but avoiding actual warfare (see Bialer, 1985; Lebow, 1983; Mack, 1985; Nincic, 1985; Stein, 1985; Volkan, 1985), although relatively low-cost wars such as the Spanish-American war (Cotton, 1986) and Grenada may be highly popular with the public. 5

While the evidence is somewhat contradictory, the economic effects of military spending also appear to be advantageous to ruling elites, at least in the United States. Several studies show that military spending is advantageous to ruling elites in the U.S. as it tends to accelerate short-term economic growth and reduce unemployment levels which can be an effective vote-getting device (Cusack and Ward, 1981; Lindgren, 1984; Nincic, 1982:32; Nincic and Cusack, 1979; however see Krell, 1981; Zuk and Woodbury, 1986). Evidence also suggests that ruling elites use increased military expenditures to counteract cyclical periods of economic decline (Cusack and Ward, 1981; Cypher, 1974; Lindgren, 1984; Nincic and Cusack, 1979; Smith, 1977; however see Krell, 1981).

Military spending in the Soviet Union is, however, clearly detrimental to even short-term economic growth (Johnson and Wells, 1986; Nincic, 1982:81). This means that military allocations are often manipulated to boost the economy during periods of decline or at the beginning and end of five-year economic planning cycles when the Soviet ruling elite wish to promote a successful image for these plans (Cusack and Ward, 1981; Nincic, 1983). Nevertheless, military interests in the Soviet Union have a dominant place in the highest levels of government (Aspaturian, 1973).

The interests of economic elites also appear to be served by the arms race although to varying degrees depending on their involvement with the military-industrial complex. In the United States, elites in industries with substantial Department of Defense contracts clearly gain from an intensified arms race (Cannon, 1975; DeGrasse, 1983; Galloway, 1973; Melman, 1971; Nincic, 1982; Kurth, 1973; Proxmire, 1970; Purcell, 1972; Weidenbaum, 1974). A growing body of evidence also suggests that increased military expenditures and arms races are favorable to large corporations that are not intimately involved with arms production (Reich, 1973), especially the largest oligopolistic multinationals (Galloway, 1973). Galloway (1973:282) concludes that "while war, or at least general war, itself is antithetical to the interests of multinational enterprise as it was to high finance in the 19th century, the perpetuation of various arms races seems quite functional." Furthermore, the greatest burden of military spending is borne not by large corporations, but by the U.S. consumer (Boulding, 1970; DeGrasse, 1983; Russett, 1970).

Numerous studies have demonstrated that military spending and especially arms races result in trade-offs that adversely effect the civilian economy while transferring resources to military-industrial interests. Military expenditures have been shown to adversely effect economic growth, employment, exports, inflation and social welfare programs including health, education, and housing (A. Becker, 1981; Johnson and Wells, 1986; Lindgren, 1984; Melman, 1974, 1979, 1986; Mosley, 1982, 1985; Nincic, 1982; Russett, 1982; Wolpin, 1983). While significant tradeoffs occur in industrial capitalist and socialist states, as well as Third World nations, each political system seems to absorb the economic consequences in different ways (Russett, 1970).

Since elites have greater control over information and policy than other classes, they can both direct policy to stimulate the arms race, and present the arms race to the public as necessary or inevitable. The policy of elites in the United States has been to stimulate the arms race while attempting to deceive the American public (see Cannon, 1975; Holzman, 1982; Lifton and Falk, 1982; Stegenga, 1987). As expected, this has especially become apparent since the attainment of MAD in the late 1960s. The modification of ICBMs with highly accurate multiple independently targeted reentry vehicles (MIRVs), as well as the deployment of cruise missiles in the early 1970s, increased the destructive capacity of the U.S. nuclear arsenal to many times that required by MAD (Nincic, 1982:94). The use of counterforce doctrine to justify weapon systems such as Maneuverable Reentry Vehicles (MARVs), MIRVs, and the Cruise and MX missiles during the late 1970s and early $80 \mathrm{~s}$ has continued this trend towards destabilization (Nincic, 1982:95-107; Sheehan, 1983:38-41). Military and governmental propaganda that has been used in attempts to sway public opinion towards these policies include the claim that the Soviets had achieved nuclear weapons superiority creating a "window of vulnerability," that counterforce programs would have a stabilizing effect (e.g., the MX as the "Peacekeeper"), and that limited nuclear war was a strategic possibility (Nincic, 1982:16-18; Powers, 1982; Sheehan, 1983:32-36). 
Despite an aggressive approach by the Reagan administration, public uncertainty has persisted concerning these arguments and the obvious threat of counterforce programs to nuclear stability. This stimulated massive opposition to programs such as the $M X$ and Cruise missiles in both the U.S. and Western Europe. The Reagan administration has responded by toning down its rhetoric and by arguing that these programs are necessary as "bargaining chips" in nuclear negotiations. Reduced versions of most of the counterforce programs have been passed through Congress.

The Strategic Defense Initiative program, or SDI, seems to be a response by the Reagan administration to both the strategic and public relations problems involved with recent military programs. SDI has an almost limitless potential for expansion and should lessen public concern by transferring the arms race from earth to space and by emphasizing "defensive" rather than "offensive" weapons systems. SDI provides elites in the United States with forceful propaganda to rationalize the continuation of the arms race. The cost of research, development, production, and deployment of SDI undoubtedly will be exorbitant (Blechman and Utgoff, 1986-87; Drell, et al., 1984).

Soviet defense doctrine, like American defense doctrine, has been used as a rationale for the production of new weapons systems. Soviet defense doctrine calls for a relatively greater destructive capability, providing a rationalization for continued nuclear arms expansion because the Soviets have always lagged behind the Americans (Nincic, 1982:Chapter 4). Unlike in the U.S., the Soviet buildup required less public deception. American arms production provided a convenient rationale to Soviet responses, while their political system actively discouraged overt dissension.

However, elite interests in modern industrial nations are much more diverse than in the past. Elite coalitions form around a vast array of concerns, many of which have little relation to the arms race or intergroup competition. Some elites in the United States actively oppose the arms race and nuclear weapons proliferation. Fitch (1985) has presented evidence suggesting that conflicts between militaryindustrial and civilian elites are increasing in the United States. Similarly, elite coalitions in the Soviet government vary in their support of military programs (Aspaturian, 1973; M. Deane, 1977; Strode and Strode, 1983; Warner, 1977).

Nevertheless, evidence persists that the most powerful elite coalitions continue to coalesce around military-industrial concerns (Fitch, 1985; Mills, 1956; Regehr, 1980; Stegena, 1987). Disagreements do occur over particular matters of policy even within elite coalitions of the military-industrial complex. The philosophical differences between the two major political parties in the United States illustrates a divergence of interests among ruling elites (Stegena, 1987). Disagreement between military and ruling elites can be observed in the frequent trimming of Pentagon requests for increased military spending by Congress or the president. Other examples of divergent interests within the military-industrial complex include the misappropriation of governmental funds by defense contractors, and competition between the various branches of the military over weapons systems and military appropriations.

\section{The Proximate Mechanisms of Arms Race Behavior}

While many elites clearly benefit from the arms race, its continuation past MAD cannot be attributed solely to conscious self-interested behavior by the elite. While actual warfare may often be unpopular with the citizenry, intergroup rivalries and hostilities seem to be highly popular (Bialer, 1985; Erikson, 1966, 1985; Stein, 1985; Volkan, 1985). Furthermore, people seem to easily give up their autonomy to authorities and are often complacent in protesting elite policy even when it is obviously detrimental to their interests (E. Becker, 1973; Freud, 1922; Johnson, 1986, 1987a, 1987b; Post, 1986; Volkan, 1985). These observations can be accounted for by a variety of proximate behavioral/psychological mechanisms that enhance the ability of elites to manipulate the citizenry and promote intergroup competition. Given the relatively small number of generations that have passed since the Terminal Pleistocene, it is likely that these proximate mechanisms evolved when humans lived in small kin groups.

A variety of psychological mechanisms seem to promote a strong concern with in-group/out-group affiliations (Edelman, 1983; Erikson, 1966; Mack, 1983, 1985; Volkan, 1985). Human psychology promotes strong positive affiliations with the group to which an individual belongs and strong negative affiliations to outside groups, especially if they are viewed as a threat. The evolutionary origins of this mechanism seem obvious, since for most of human evolutionary history the in-group was made up of close kin, so that strong positive affiliations promoting altruism were favored due to kin selection. Members of out-groups would have been feared and mistrusted because they were genetic competitors, especially if intergroup competition for resources was important. These factors represent the evolutionary origins of ethnocentrism, racism, nationalism, and patriotism (Johnson, 1986; Reynolds et al., 1987; van den Berghe, 1981; Willhoite, 1977). 
People are socialized to identify certain symbolic, ideological, behavioral, and physical characteristics with group membership. Johnson (1986, 1987a; Johnson et al., 1987) has argued that socialization to membership in groups larger than the family involves the manipulation of kin recognition cues that evolved when humans lived exclusively in small kin groups. Individuals have evolved to behave altruistically to close associates and to individuals with a high degree of shared physical and behavioral characteristics. In traditional societies these individuals are close family members and altruism is favored due to kin selection. In complex societies, in-group affiliation and altruism towards groups made up primarily of non-kin, are promoted by using these cues. Individuals are socialized to identify strongly with particular symbols (flags, patriotic songs), ideas ("freedom," "democracy"), behaviors (language, cultural "norms"), and physical traits (skin color) associated with the group. The tremendous symbolizing ability of humans allows in-groups and outgroups to be continually redefined (Emmert, 1986; Willhoite, 1977).

The psychological mechanisms that promote outgroup fear, distrust, and aggression are related to mechanisms involving in-group conformity. Agonistic feelings towards members of other racial, ethnic, or religious groups, and other nations involve projection, displacement, and externalization of negative feelings towards one's own group, promoting ingroup cooperation (Stein, 1985). Thus, agonistic emotions towards out-groups should increase as a result of both internal and external unrest. Differences between members of competing groups are often stressed, exaggerated, or fabricated such that the "enemy" is dehumanized and group solidarity confirmed (Erikson, 1966; Volkan, 1985).

The nature of dominance/deference relationships in complex societies also seems to be based on psychological mechanisms that evolved in smallscale societies (Johnson, 1987b; Tiger, 1970; WilIhoite, 1976, 1977, 1986). In traditional societies authority is primarily parental (Johnson, 1987b). Parental authority is based on protection, provisioning, discipline, and conflict mediation involving children (Johnson, 1987b; Trivers, 1974). Thus, if dominance/ deference relationships evolved around parent-child relationships, then individuals who trigger cues involving parental authority should be able to elicit deferential reactions. Likewise, individuals should be predisposed to relinquish control and relate to authority figures as if they were parents. Psychological evidence supports these hypotheses concerning the relationship between political and parental authority in modern industrial nations (E. Becker, 1973; Freud, 1922; Johnson, 1987a; Johnson et al., 1987; Miller, 1983; Mack, 1985:315; Volkan, 1985).
In complex societies the promotion of strong positive in-group and negative out-group affiliations and obedience to authority is especially advantageous to elites because they benefit the most from intergroup competition and intragroup cooperation. The use of kin terms such as "motherland" and "fatherland" in patriotic speech is an obvious example of the use of kinship cues by elites to promote strong in-group affiliations (Johnson, 1986, 1987a). Ruling elites also promote abstract symbols of authority because they cloud the relationship between their interests and political decision making (Edelman, 1964). Humans have an incredible ability to use belief systems to rationalize their behavior so that it appears to be in the common interest. This form of self-deception may enhance the ability of those in power to deceive the public because they actually believe that what they are doing is necessary for the common good (see Glad, 1983; J. Rosenberg, 1986). A psychological predisposition to view authority as parental may also explain why nonelites so easily accept elite ideologies.

These psychological mechanisms promote the nuclear arms race by accentuating intergroup hostilities and competitiveness and by encouraging people to surrender control to authorities. Even more dangerous is the observation that in-group conformity, out-group agonistic behavior, and the tendency to defer to authorities are intensified as a result of anxiety and especially out-group threats (Mack, 1985; Post, 1986; Volkan, 1985). Developmentally, various forms of anxiety also seem to produce personalities that are prone to strong ingroup/out-group affiliations and authoritarianism ( $E$. Becker, 1973; Earle, 1986; Feshbach and White, 1986; Freud, 1922; Glad, 1983; Klugman, 1985; Peterson, 1983; Post, 1986; Ross, 1986). This suggests that superpower competition and conflict might actually act to enhance those psychological mechanisms that serve to promote the arms race (see Goodman et al., 1983; Mack, 1985, 1986).

\section{Arms Races, Elite Interests, and Differential Reproduction}

The preceding analysis has argued that the intensification of the arms race is stimulated by intergroup competition, intragroup cooperation, and elite authority which is maintained not only by coercion, but by a variety of proximate behavioral/psychological mechanisms. These mechanisms are evolutionary legacies of a history of living in small competitive family groups where they acted to maximize inclusive fitness. The drastic changes in human social environments which have occurred during the past 12,000 years may have created novel evolutionary environments. However, the ability of humans to profoundly manipulate their environment, particu- 
larly socially and symbolically, may have allowed us to construct new environments that are consistent in many ways with those of our evolutionary history (Fox, 1979).

If these proximate mechanisms continue to function adaptively, then elites who accrue more resources should use them to maximize reproduction. This hypothesis has been supported by field research among numerous small-scale societies (Borgerhoff Mulder, 1987; Chagnon, 1979a, 1980, 1982; Flinn, 1983; Irons, 1979; Kaplan and Hill, 1985; Turke and Betzig, 1985; Wrangham and Ross, 1983) and from worldwide cross-cultural samples (Betzig, 1982, 1985; J. Hill, 1984). These studies demonstrate that, in these societies, elites with preferential access to resources outreproduce non-elites.

Betzig (1982, 1985; also see Faux and Miller, 1984; Mealey, 1985) has presented evidence suggesting that elites in emergent states with socially stratified societies outreproduce other individuals greatly. However, this trend towards an increasing degree of differential reproduction between elites and less powerful individuals ceases with modern industrial states. Betzig (1982:217) argues that at some point in social evolution, a threshold is reached where inequitable impunity in intragroup conflicts and degree of differential reproduction both decline as group size and social complexity increase. This change in reproductive strategies seems to be linked to the modern demographic transition and a shift towards more K-selective strategies in modern industrial nations (Alexander, 1974).

The change in reproductive strategies may have resulted from the intensification of intergroup competition necessitating increased intragroup cooperation. Under these conditions, greater reproductive equity among individuals would have been advantageous, especially to elites, by promoting intragroup cooperation. ${ }^{6}$ Nation-states are unique among human groups in that nepotistic relationships are suppressed and reciprocal interactions provide group cohesion. Alexander $(1979,1985,1987)$ has argued that moral systems are systems of indirect reciprocity which promote cooperation between group members even if they are unrelated. The general function of laws seems to be the maintenance of order in the interest of preserving group unity (Alexander, 1978, 1979). The increasing specialization of labor may also make many individuals less replaceable (Betzig, 1982).

The availability of highly reliable contraception is undoubtedly a major factor in altering human reproductive strategies. Contraception allows people, and especially elites, to follow proximate mechanisms, such as acquisition of resources and sexual intercourse, without reproducing. These proximate mechanisms evolved because they allowed individu- als to maximize reproductive success in the environments of the past. It is not counter-Darwinian if these mechanisms no longer promote inclusive fitness, it means only that people are faced with novel environments and new selective pressures (Fox, 1986).

Despite the factors relating to the modern demographic transition, evidence suggests that the most powerful elites continue to outreproduce other individuals. The relationship between resource acquisition and reproductive success in modern nationstates has been a complex and hotly contested issue (Barkow and Burley, 1980; Daly and Wilson, 1983, 1986; Gaulin, 1986; J. Hill, 1984; Irons, 1986; Kaplan, 1985; Kaplan and Hill, 1986; Vining, 1986). However, a growing number of studies show a correlation between wealth and reproductive success in industrial nations (Daly and Wilson, 1983; Easterlin, 1980; Essock-Vitale, 1984), while those that refute this relationship suffer from problems that do not allow adequate hypothesis testing (Bajema, 1986; Gaulin, 1986; Ghiselin and Scudo, 1986; Kaplan and Hill, 1986).

This correlation seems to be strongest for the most powerful elites (Kirk, 1957; Sly and Richards, 1972). Essock-Vitale (1984) examined a sample of four hundred individuals in the United States with a mean net worth in excess of $\$ 250,000,000$. After considering both differential reproduction and survivorship, Essock-Vitale (1984:47) concludes that the wealthy sample was reproducing at a rate of 20-38 percent greater than other segments of society each generation. This data has led one of the most adamant critics of positive correlations between cultural and reproductive success to conclude that "the available quantitative evidence would appear to show higher fitness among the nation's economic, political, social, and technocratic elite... and its wealthiest citizens..." (Vining, 1986:173). These data support strongly the hypothesis that elites use their preferential access and control over resources to maximize reproduction relative to the general population. This provides direct support for a causal model in which the ultimate cause of arms race behavior is natural selection which has patterned human behavioral response mechanisms so as to maximize inclusive fitness.

\section{Conclusion}

I have used a Darwinian theoretical perspective to examine the evolution of arms race behavior which has culminated in today's nuclear arms race (fig. 1). This has required an examination of the evolution of human sociality in terms of the selective pressures favoring particular social forms. The development of social complexity is argued to be the result of escalatory intergroup competition over optimal re- 
source patches which was triggered by a variety of environmental changes during the Terminal Pleistocene/Early Holocene.

This model of social evolution incorporates many of the classic arguments concerning the rise of social complexity (see McGuire, 1983; Wenke, 1981). Many of the variables that cultural evolutionists have defined as measures of "sociocultural progress," including increasing population size, productive intensification, and social stratification (Carneiro, 1970b; Sahlins and Service, 1960; Service, 1971, 1975; Steward, 1949, 1968; White, 1949), are theoretically linked by focusing on the processes of change in human behavior. Carneiro's (1970a) arguments concerning social and environmental circumscription and the effects of warfare in the rise of the state; M. Cohen's (1977) ideas concerning demographic packing; and the suggestions of $\mathrm{H}$. Wright (1977), Binford (1972), and Hayden (1981) concerning the impact of environmental change are all incorporated in this model. Wittfogel's (1957) arguments concerning irrigation and Rathje's (1971) concerning trade can be viewed as components of productive intensification. Marxist ideas on class conflict (Engels, 1972; Friedman and Rowlands, 1977; Godelier, 1978; Marx, 1906; Marx and Engels, 1972; Patterson and Gailey, 1987) also figure prominently in the model presented in this article.

The rise of social complexity was indeed, as R. M. Adams (1966), Flannery (1972, 1986), Hassen (1981), and Redman (1978) argue, the result of a multiplicity of factors. Viewing social evolution in terms of ultimate causation, however, allows these factors to be integrated around the concept of adaptation or inclusive fitness maximization. Natural selection produces individuals who behave so as to maximize inclusive fitness. Therefore, except under evolutionarily novel conditions, individuals will respond to environmental perturbations so as to maximize reproduction relative to competitors.

Since a Darwinian perspective focuses on the processes of individual adaptation it avoids the various criticisms which have been leveled at systems theory (Athens, 1977; Dunnell, 1978, 1980, 1982; McGuire, 1983; Rindos, 1984), especially the problem of group selection (Orlove, 1980; Richerson, 1977; Vayda, 1983; Vayda and McCay, 1975). Thus, the rise of powerful elites in stratified societies is not explained in terms of how they functioned within a social, cultural, or ecological system. Instead, it is seen as a result of their ability to exploit resources from the rest of society in order ultimately to outcompete other individuals reproductively. Revolutions occur when the risk to lower classes of continued exploitation becomes sufficiently great to exceed the risk of rebellion.
Darwinian theory also provides an alternative to the population pressure argument, which too often is used by systems theorists as a cause for any and all sociocultural change. Rather than the relative availability of resources in the environment, it is the distribution of resources in time and space that determines whether intensive intergroup competition will be adaptive to individuals, thereby setting off the complex series of interactions leading to the development of social complexity. Resource scarcity is a limiting factor when it does occur, but that would seem to be very rare in human history and, at least recently, most often the result of humans exploiting other humans. Furthermore, when viewed from a systems or population level perspective humans may often seem to be exploiting resources sub-optimally. During the Pleistocene, r-selected resources were undoubtedly present in the environment and exploited by human populations. If the system or the multigenerational population was the unit of adaptation, then a shift towards the exploitation of these resources would probably have been advantageous because of their relative productivity. However, it is the individual rather than a system or population that adapts to environments (Richerson, 1977). Developing the necessary technology and information to make an adaptive shift towards an emphasis on the exploitation of these resources and away from medium-to-large bodied mammals would have put these individuals at a competitive disadvantage relative to individuals maintaining the traditional economies. This is why this shift did not occur until Terminal Pleistocene/Early Holocene environmental change made it advantageous for individuals.

By utilizing an evolutionary perspective, the nuclear arms race can be seen along a continuum of arms races in human history which are manifestations of the more general phenomenon of escalatory intergroup competition. Intergroup competition has had a significant impact on human sociality. Until recently, human intergroup competition has not threatened species survival as the nuclear arms race now does. The critical problem is that, for the majority of human evolutionary history, the behaviors which stimulate the nuclear arms race (i.e., xenophobia, in-group affiliations, intergroup competition, submission to authority) were adaptive to individuals. Natural selection has never operated so as to prevent species extinction (Alexander, 1987). Instead, it produces individuals who behave in ways that maximize their inclusive fitness even if this enhances the chances of species extinction. While these behaviors may continue to be adaptive in the short-term, especially for many elites, they are placing humanity in considerable risk of sudden extinction. There is hope in that human behavior is sufficiently flexible to allow individuals to forgo their immediate interests. 
In terms of the nuclear arms race, this will be in our long-term reproductive interests if it allows us or our descendents to survive rather than perish.

Individuals should not be expected to oppose the arms race unless they perceive it to be a significant threa to themselves and their families. The achievement of MAD by the superpowers should have provided a check to the nuclear arms race by eliminating its advantages. The intensification of the arms race past $M A D$, coupled with the direct and indirect benefits that the elite derive from it, indicates that for them the risks do not outweigh the benefits. This suggests that the nuclear arms race will continue until it is no longer advantageous to the elite or until a nuclear war occurs. Male-domination of foreign policy elite positions may exacerbate this problem as male reproductive strategies generally involve more competition and risk than female strategies (Daly and Wilson, 1983; Masters, 1987).

The economic effects of the nuclear arms race suggest that its continuation may be less destructive to the United States than to the U.S.S.R. The U.S. economy benefits at least cyclically from military programs, while the Soviet economy clearly suffers (Nincic, 1982:81). This may partially explain why the Soviet Union has usually refrained from initiating new weapons systems, instead choosing to wait and respond to developments in American nuclear arms policy. A fear of the economic consequences of an "arms race in space," may also explain the strong Soviet opposition to SDI. This suggests that Soviet elites may perceive the intensification of the nuclear arms race as a threat to their interests prior to their American counterparts.

The Soviets can hope that middle- and lower-class concerns in the U.S. change so as to curb the intensification of nuclear arms production. This may be possible since people in the United States have some input into policy and greater access to information, giving the elite less efficient control over military policy. The Soviets will attempt undoubtedly to influence the American public concerning these issues. However, proximate mechanisms that compel people towards intergroup competition, intragroup cooperation, and submission to authority may make it difficult to pressure elites into altering policy in both nations.

The exploitation of the majority of the people by the elite may result in increasing social unrest (see Melman, 1986). Both the U.S. and the U.S.S.R., however, have increasingly looked to the Third World for resources, intensifying the exploitation of the peoples of these nations while insulating their own people. Conditions in Third World countries are increasingly making social revolutions viable. The incidence of revolutions and revolutionary movements in Central America, Africa, and Southeast
Asia supports this contention. However, superpower politics may make it virtually impossible for a Third World country to break away from superpower domination. Unfortunately, under present conditions, it seems unlikely that Third World revolutions or internal unrest will place sufficient pressure on elites to compel them to curb the arms race in the near future. ${ }^{7}$

This article has focused on the evolutionary or ultimate causes of human arms race behavior, how it has manifested itself hitorically, and especially so in the context of the nuclear arms race. Many proximate factors, however, such as specific economic, political, and behavioral mechanisms have not been adequately treated. Furthermore, arms race behavior is manifest not just in the nuclear arms race but in conventional arms races throughout the world. The problems resulting from human intergroup competition are immensely complex and operate on many different levels. While a solution is unlikely in the near future, the scientific study of this behavior is crucial. Without knowledge of both the proximate mechanisms and ultimate causes of human behavior we are increasingly vulnerable to social manipulation and will be unable to alter behavior in an effective and constructive manner. Unfortunately, this endeavor will not be without risk as it is this kind of knowledge that those in power are likely to suppress and use to their advantage. Regardless, a more rigorous understanding of human social behavior is absolutely necessary if a humane solution to the nuclear arms race is to be achieved.

\section{Notes}

1. I would like to thank the many individuals who assisted me in the preparation of this article. Kurt Kalb originally piqued my interest in Darwinian social theory and discussions with him have greatly influenced my thinking on social evolution. Extensive discussions with Rob Blumenschine and Horst Steklis were of great help, and allowed me to put together a more succinct and clear argument. Wendy Ashmore, Robin Fox, Roger Masters, Heather Strange, Lionel Tiger, Marc Winter, and several anonymous reviewers made helpful comments on earlier drafts.

2. The founding of the Journal of Conflict Resolution in 1957 and the Journal of Peace Research in 1964 can be seen as a result of this increased concern.

3. When confrontations occurred they may have been violent (Roper, 1969), but given the archaeological evidence it is unlikely that this involved organized warfare (Toth, 1987). 
4. During this period war involvement has been common regardless of regime type (Chan, 1984 Hass, 1965; Weede, 1984), although Geller (1987) indicates that personalist nations have been more likely to engage in long-term conflict than either polyarchic or centrist states. The longest episodes of relative peace usually followed decisive victories in warfare (Maoz, 1984).

5. Recent U.S. presidents have tended to suffer at the polls if they involved the nation in a major war (Cotton, 1986). However, the greatness of a president as measured from public opinion polls is highly correlated with the years that his administration was involved in a war (Simonton, 1986). This suggests that while actual warfare induces hardships and internal unrest, the concept of conflict and warfare carries great symbolic and emotional weight.

6 . This relative decline in elite reproductive success would have been particularly adaptive if failure to respond to the unrest of the citizenry resulted in revolutions (although this was only one among many concessions made by the elite). The demographic transition does seem to correspond in time with the end of the great revolutionary movements of the eighteenth, nineteenth, and early twentieth centuries.

7. This should not be read as a discouragement of the antiwar or antinuclear movement. At present, these seem to provide the best hope for influencing people to curb the arms race. Falger (1987) suggests that people might be redirected to see the enemy as the weapons themselves rather than other people. I would say that this is more adaptive in the longrun and is exactly what has happened for many of the people in the antiwar and antinuclear movements. The key is to educate more people, especially elites, to this fact. 